\title{
STRUCTURE AND THERMAL BEHAVIOR OF TANNINS FROM Acacia dealbata BARK AND THEIR REACTIVITY TOWARD FORMALDEHYDE
}

\author{
JUSTO LISPERGUER ${ }^{1,2 *}$ YANINA SARAVIA' ${ }^{2}$ EMILIO VERGARA ${ }^{3}$ \\ ${ }^{\prime}$ Facultad de Ciencias, Departamento de Química, Universidad del Bio-Bio, Av Collao 1202 Concepción, Chile \\ ${ }^{2}$ Centro de Investigación de Polímeros Avanzados, CIPA. Conicyt-Regional R08C1002. Av. Collao 12, Concepción, Chile. \\ ${ }^{3}$ Centro de Investigación en Tecnologías de la Construcción, Universidad del Bio-Bio. Av. Collao 1202, Concepción, Chile.
}

\begin{abstract}
The objective of this study was to evaluate the tannin extraction potential taken from the bark of Acacia dealbata. This tannins were extracted with water at $90^{\circ} \mathrm{C}$. An extraction yield of $17.2 \%$ solids with a Stiasny number of $82 \%$ was obtained from the bark extract of Acacia dealbata. The structure was studied by Fourier transform infrared spectroscopy (FTIR). The thermal behavior of tannins was studied by DSC and a glass- transition temperature $\left(\mathrm{T}_{\mathrm{g}}\right)$ of $116,77^{\circ} \mathrm{C}$ was determined. The thermal stability of tannins was studied by TGA. At $196.91{ }^{\circ} \mathrm{C}$ the decomposition is $3.7 \%$ and the maximum of the weight loss rate (DTG) of the degradation was $257.77^{\circ} \mathrm{C}$. The curing with formaldehyde showed an exotherm reaction in the range of $100-120^{\circ} \mathrm{C}$, which is similar to tannins of other species.
\end{abstract}

Keywords: Tannins, Acacia dealbata bark, Structure of tannins, Thermal behavior.

\section{INTRODUCTION}

The potential of tannins, particularly those extracted from bark, has long been recognized to substitute more expensive petrochemical-derived components such as phenol-formaldehyde, resorcinol-formaldehyde or ureaformaldehyde, in adhesives for wood gluing applications ${ }^{1-6}$. Tannins are natural polyphenolic materials, composed mostly of flavan-3ol repeating units and smaller fractions of polysaccharides and sugars. These polyphenolic materials can be hardened by reaction with formaldehyde or hexamethylenetetramine (HEXA), as crosslinking agents ${ }^{7,8}$. Examples of tannin use in thermoset adhesive applications include partial or full replacement of phenol formaldehyde resin in hot -pressing of products such as plywood and composite panels, and the partial substitution of resorcinol in adhesive resins ${ }^{9,10}$.

Studies that report the behavior of these adhesives for the manufacture of molding powers or fiber composite materials are scarce in the open literature ${ }^{11}$.

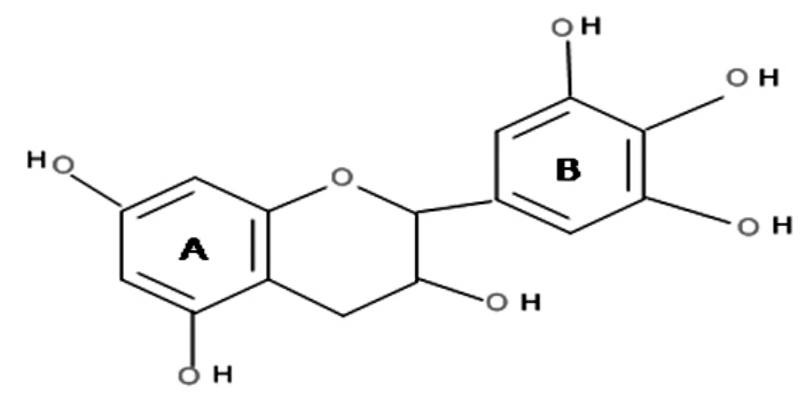

Figure 1. Flavan- 3ol repeating unit in polyflavonoid tannins.

The reaction of HEXA with tannins was studied by Pizzi, who showed that HEXA is not a formaldehyde-yielding hardener and thus it lead to cured products with low formaldehyde emissions. The crosslinking reactions proceed by formation of reactive HEXA fragments or intermediates that react with phenolic nuclei of the polyflavonoid tannins ${ }^{1}$.

The most widely used as industrial tannins are obtained from the wood and bark of the quebracho tree (Schinopsis balansae, Argentine) and from the bark of mimosa (Acacia mearnsii, Brazil and South Africa). Resorcinolictype tannins such as those derived of wattle or quebracho species tend to only find applications in hot pressing ${ }^{11}$. Other tannins obtained from pine species with phloroglucinolic structures, have and additional hydroxyl group on the A- ring of the tannin flavonoid unit giving greater reactivity allowing use in ambient temperature curing (cold set adhesives). Phloroglucinolic-type tannins, compared with resorcinolic type tannins, have found little commercial use, due to undesirable characteristic as high reactivity with formaldehyde and high viscosity ${ }^{1}$
Phenol-formaldehyde based wood adhesives still today dominant in European markets. However, the necessity to diminish petrochemicals consumption stimulate the search of alternative environmentally safe adhesives. The antimicrobial properties of tannins make their application in wood composites and adhesives industry very attractive ${ }^{12}$.

In this work, we have investigated about the isolation, structure and thermal behavior of tannins from Acacia dealbata bark. We also studied the reactivity of the tannins toward formaldehyde.

\section{EXPERIMENTAL}

\section{Extraction method}

$100 \mathrm{~g}$ of ground bark from Acacia dealbata and $1700 \mathrm{~mL}$ of water were placed in a flask and heated at $90^{\circ} \mathrm{C}$ with mechanical stirring during 6 hours. Once extraction time was completed, the extraction liquor was separated from the solid residue by filtration. The solid residue was then washed four times and washing waters were evaporated in an oven at $100^{\circ} \mathrm{C}$ overnight.

Determination of polyphenols by the Stiasny reaction

The Stiasny number reaction was used to determine the polyphenol content of extracts. Fifty milliliters of $(15 \% \mathrm{w} / \mathrm{w})$ tannin solution was pipeted into a 250 $\mathrm{ml}$ flask. $10 \mathrm{ml}$ of aqueous formaldehyde $(37 \% \mathrm{w} / \mathrm{w})$ and $5 \mathrm{ml}$ of hydrochloric acid solution $(10 \mathrm{M})$ were added and the mixture was heated under reflux for 30 $\mathrm{min}$. The reaction mixture was filtered through a sintered glass filter (porosity 2 ) whilst it was still hot. The precipitate was then dried in an oven at $105^{\circ} \mathrm{C}$ to constant weight. The Stiasny number is the ratio of the oven-dried weight of the precipitate to the total dissolved solid content of the tannin extract expressed as a percentage.

FT-IR analysis

Tannins from dried extract of Acacia dealbata were analyzed by Fourier transform infrared spectroscopy (FT-IR) on a Perkin Elmer FT-112 Spectrum Two instrument to characterize functional groups of tannins.

\section{TGA and DSC analysis}

To determine the thermal behavior of tannins, a dynamic test was carried out with a TGA Q 50. The samples, with an average mass of $8 \mathrm{mg}$, were heated from $25 \mathrm{a} 600^{\circ} \mathrm{C}$ at a heating rate of $10^{\circ} \mathrm{C} / \mathrm{min}$ under a nitrogen atmosphere. The thermal stability of tannins was studied.

The glass-transition temperature ( $\mathrm{T}_{\mathrm{g}}$ ), was studied with a DSC 822e Mettler Toledo equipped with a data analyzed software STARe. For this purpose, the ASTM 3418 was applied within a range of 25 and $200^{\circ} \mathrm{C}$ at a heating rate of $20^{\circ} \mathrm{C} / \mathrm{min}$, under a nitrogen atmosphere.

Curing reaction of tannins adhesives

Tannin solution was prepared and $10 \%$ of powdered paraformaldehyde, by weight of dry tannin extract, was added. $\mathrm{NaOH}$ was added until a $\mathrm{pH}$ of 11 . The sample was sealed under air in $120 \mu \mathrm{L}$ medium pressure stainless steel crucible with a Viton O-ring which can withstand pressures up to $2 \mathrm{MPa}$. The temperature of the DSC was scanned from $25^{\circ} \mathrm{C}$ to $250^{\circ} \mathrm{C}$ at a heating rate of $10^{\circ} /$ min under a nitrogen atmosphere. 


\section{RESULTS AND DISCUSSION}

\section{Solids and polyphenols content of the bark extract}

An extraction yield of $17.2 \%$ solids was obtained from the bark extract of Acacia dealbata. This value is slightly less than those mentioned for mimosa and Pinus radiata barks (i.e. $42.5 \%$ and $20 \%$, respectively) ${ }^{13,14}$

The mean values of polyphenols content determined by the Stiasny method, was $82 \%$. This value is also similar to that found for other species ${ }^{15}$.

Grace pomace also been used to obtain tannins. These extract have a considerable proportion of nonphenolic materials, mainly simple sugars and polymeric carbohydrates with low Stiasny numbers. The yield extraction in water at $120^{\circ} \mathrm{C}$ was $22.3 \%$ (oven dry mass) and the Stiasny number ranged between 32 to $55^{16,17}$.

Other researchers have reported the tannins extraction yield of Douglas fir bark of $14 \%$ in case of urea/sulphite solution. ${ }^{18}$

\section{FT-IR analysis of tannins}

In Fig. 2 the FT-IR spectrum of the tannins from Acacia dealbata bark extract are shown. The area between 500 and $4000 \mathrm{~cm}^{-1}$ was analyzed.

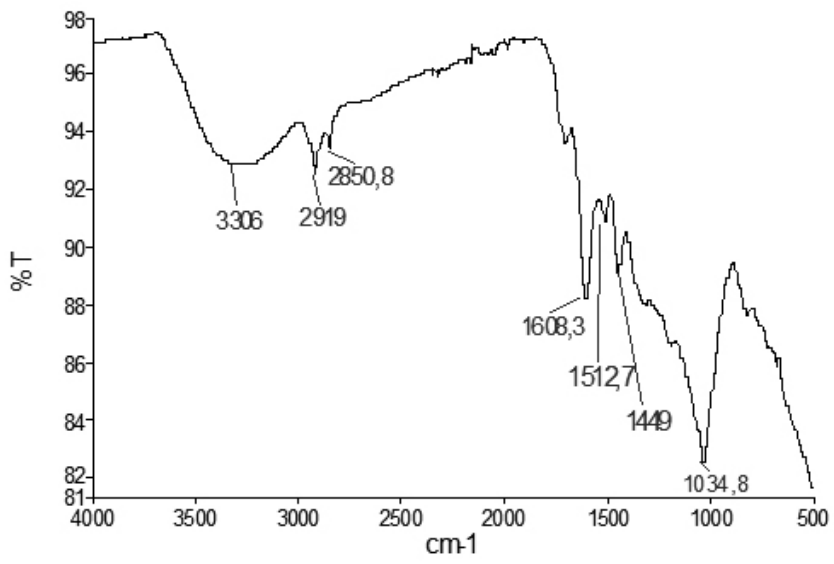

Figure 2. FT-IR spectra of tannins from Acacia dealbata bark.

In Fig. 2, it can be clearly observed a wide band at $3306 \mathrm{~cm}^{-1}$ which shows the presence of the phenolic hydroxyl groups $(\mathrm{OH}$ stretching vibrating). The 2919 and $2850 \mathrm{~cm}^{-1}$ absorption bands were attributed to $\mathrm{C}-\mathrm{H}$ and $\mathrm{CH}_{2}$ vibrations of aliphatic hydrocarbon. The $1608.3,1512$ and $1449 \mathrm{~cm}^{-1}$ absorption bands, were attributed to aromatic ring stretching vibration. The $1034.8 \mathrm{~cm}^{-1}$ absorption band, was attributed to $\mathrm{C}-\mathrm{O}$ stretching vibration. Tannins from Taiwan acacia bark shows only one band at $2933 \mathrm{~cm}^{-1}$ attributed to $\mathrm{C}-\mathrm{H}$ and $\mathrm{CH}_{2}$ vibration. ${ }^{19}$ Tannins of other species such as Pachira quinata and Pinus caribea show very similar FT-IR spectra to Acacia dealbata. ${ }^{20}$

\section{Thermal characterization}

DSC analysis

DSC is the most widely accepted method for determining the glass transition temperature of natural and synthetic polymers and generally to study the thermal behavior of a polymer. Figure 3 shows the DSC curve for tannin from Acacia dealbata bark extract obtained at a heating rate of $10 \% \mathrm{~min}$.

The $T_{g}$ of dry tannin is often more difficult to detect than in a synthetic polymer, due the complex structure of tannin and sometimes only is possible to detect the range of the change in the curve.

The $\mathrm{T}_{\mathrm{g}}$ of the tannin was determined from the change in the heating curve and it is located at $116,77^{\circ} \mathrm{C}$, the same region reported for tannins of other species as quebracho tannins where the $\mathrm{T}_{\mathrm{g}}$ was located at $126^{\circ} \mathrm{C} .{ }^{4}$ This value is also similar to the $\mathrm{T}_{\mathrm{g}}$ of lignin of Eucaliptus and Pinus radiata ${ }^{2}$.

TGA analysis measurement

In order to study the thermal stability of the tannins, runs by means of TGA were conducted.

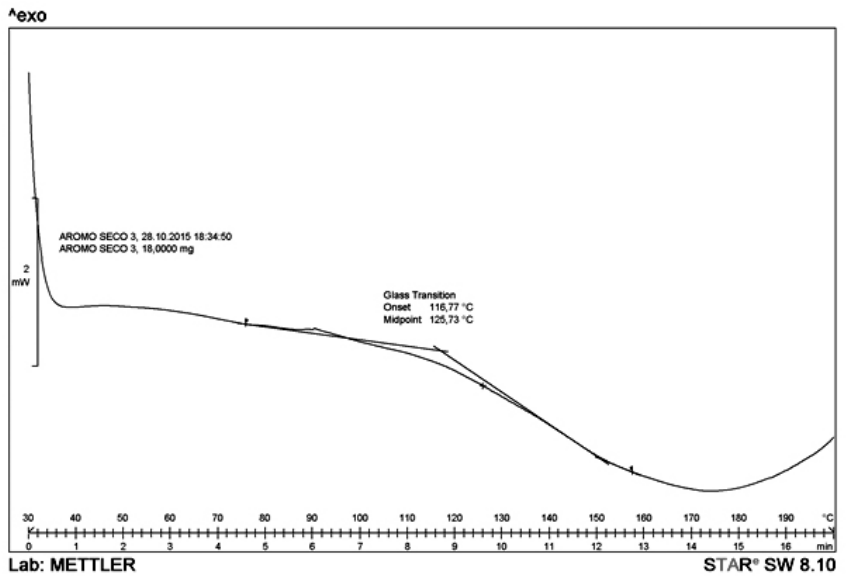

Figure 3. DSC of Acacia dealbata tannin.

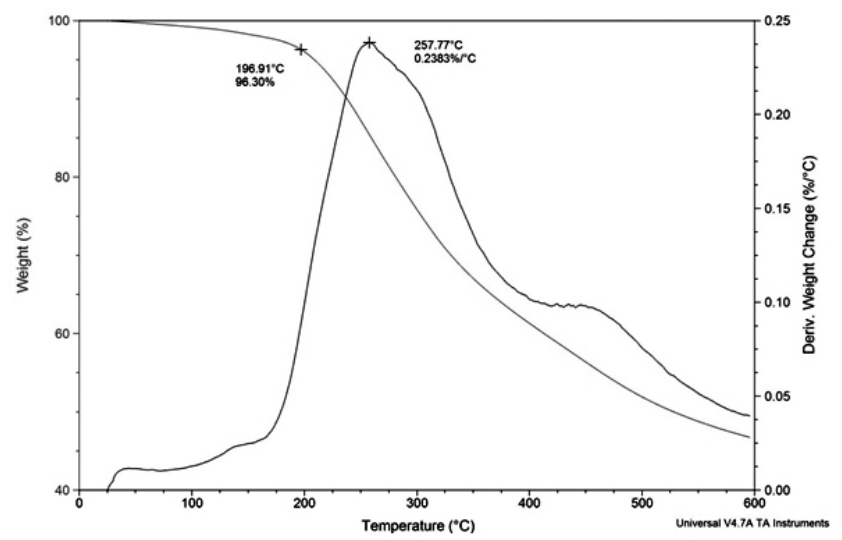

Figure 4. Decomposition curves of Acacia dealbata tannin.

As shown in Figure 4, the decomposition profile of the tannin occurred in one step. At $196.91^{\circ} \mathrm{C}$, the decomposition is only a $3.7 \%$, which can be attributed to the loss of moisture and gases absorbed and does not involve degradation of the tannins. The maximum of the weight loss rate (DTG) of the degradation, was $257.77^{\circ} \mathrm{C}$.

The complex condensed aromatic structure of tannin leads to high thermal resistance. Although the degradation is almost complete at $600^{\circ} \mathrm{C}$, tannin shows a remaining weight of about $44 \%$.

\section{Curing reaction of tannin-formaldehyde adhesives}

Figure 5 shows the DSC scan obtained at a heating rate of $10^{\circ} \mathrm{C}$ for the curing reaction of tannin with paraformaldehyde. The characteristic curing reaction shows only one peak of the exothermic reaction in the range of 100$120^{\circ} \mathrm{C}$ with a peak at $110,74^{\circ} \mathrm{C}$.

The curing reaction of tannin occurs at lower temperature than phenol formaldehyde resins $\left(145-150^{\circ} \mathrm{C}\right)$ and is more similar to the reaction curing of phenol- resorcinol formaldehyde $\left(60-120^{\circ} \mathrm{C}\right) .{ }^{22}$

The endotherm in the range of $200-220^{\circ} \mathrm{C}$ shows the thermal degradation of tannin, also shown in the figure 4 .

\section{CONCLUSIONS}

In this study, the structure, thermal properties and curing reactions of Acacia dealbata bark tannins were analyzed. An extraction yield of $17.2 \%$ solids was obtained from Acacia dealbata bark. This is slightly less than those mentioned for mimosa and Pinus radiata barks. The polyphenols content determined by the Stiasny number was $82 \%$ and it is similar to that found for other species. TGA studies show a high thermal resistance of tannins. The decomposition starts at $196.91^{\circ} \mathrm{C}$ with a DTG at $257.77^{\circ} \mathrm{C}$. DSC studies show a $\mathrm{T}_{\mathrm{g}}$ of tannin of $116.77^{\circ} \mathrm{C}$ similar to other lignocellulosic materials as lignin. The curing reactions of tannin with formaldehyde occurs in the range of 100 $120^{\circ} \mathrm{C}$ with a peak at $110.74^{\circ} \mathrm{C}$, which is similar to tannins of Pinus radiata and 
mimosa. The study of the properties of tannins of Acacia dealbata shows that it is possible to use these tannins in the formulation of adhesive resins reinforced with phenol formaldehyde.

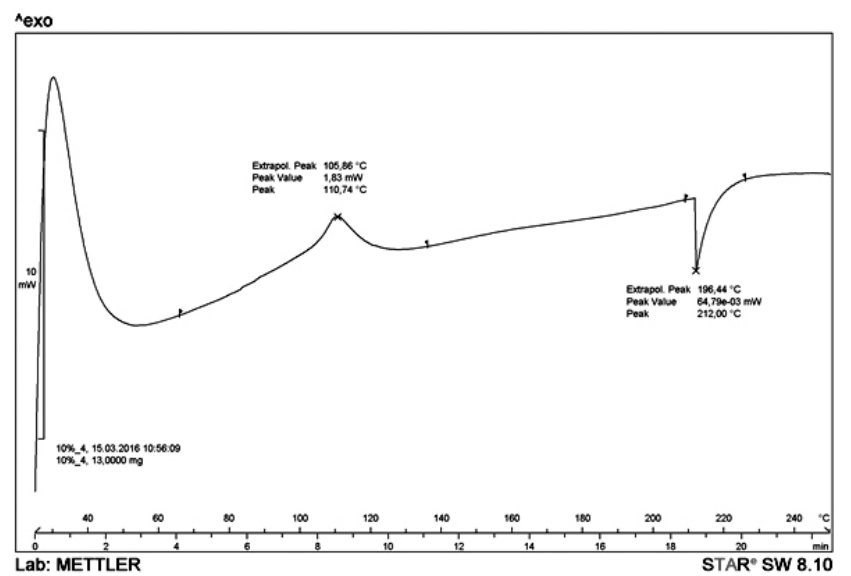

Figure 5. DSC thermogram of the curing reaction of tannin-formaldehyde adhesive.

\section{ACKNOWLEDGEMENTS}

This work was supported by a grant of the Centro de Investigación de Polímeros Avanzados, CIPA, grant R08C1002 and the grant DIUBB 146306 3/R of Bio-Bio University.

\section{REFERENCES}

1. A.Pizzi, J. Adhesion Sci.Technol. 20, 829, (2006).

2. M.H.Alma, S.S.Kelley, Polym.Degrad.Stab. 68, 413, (2003).

3. E.Roffael, B.Dix, J.Okum, Holz als Roh und Werkstoff 58, 301, (2000).

4. M.Mosiewicki, M.I.Aranguren, J.Borrajo, J.Appl. Polym.Sci. 91, 3074 , (2004).

5. M.Fechtal, B.Riedl, Holzforschung 47, 349, (1993).

6. Y. Lu, Q.Shi, Holz als Roh und Werkstoff 53, 17, (1995).

7. A.Pizzi in Handbook of Adhesive Technology, A.Pizzi, K.L.Mittal eds. Marcel Dekker, New York, 2003.

8. F.Pichelin, C.Kamoun, A.Pizzi, Holz als Roh und Werkstoff 57, 305, (1999).

9. P.M.Stefani, C.Peña, R.A.Ruseckaite, J.C.Piter, I Mondragon, Bioresource Technology 99, 5977, (2008).

10. W.J.Lee, W.C.Lan, Bioresource Technology 97, 257, (2006).

11. R. Nico, Plásticos de tanino de quebracho, Laboratorio de Ensayo de Materiales e Investigaciones Tecnológicas-LEMIT, Report 38, Series II, La Plata, Argentina, (1951).

12. A.Pizzi in Wood Adhesives: Chemistry and Technology, A.Pizzi ed.Marcel Dekker, New York, 1983.

13. A. Scalbert, Phytochem. 30, 3875, (1991).

14. W.J.Grigsby, S.J.Hill, C.D.McIntosh, J.Wood Chem. Technol. 23, 179, (2003).

15. S.Ohara, Y.Yasuta, H.Ohi, Holzforschung 57, 145, (2003).

16. L.Ping, A.Pizzi, Z. D. Guo, N.Brosse, Ind. Crops Prod. 40, 13, (2012)

17. L.Ping, A.Pizzi, Z.D. Gu0, N.Brosse, Ind.Crops Prod. 34, 907, (2011)

18. F.Bertaud, S.Tapin-Lingua, A.Pizzi, P.Navarrete, M.Petit-Conil, Cellulose Chem.Technol. 46, (7-8), (2012)

19. W.J.Lee, W.C. Lan, Bioresource Technol. 97, 257, (2006)

20. J. Aguilar, J. Jaen, A.Vargas, P.Jiménez, L. Vega, J.Herrera, H.Borbón, R, Soto, Tecnología en Marcha 25, (4), 15 (2012)

21. J.Lisperguer, P.Pérez, S Urizar, J.Chil.Chem.Soc. 54, 460, (2009)

22. J. Lisperguer, C. Droguett, B. Ruf, J.Chil.Chem.Soc. 50, 375, (2005). 